\title{
Unreal experiences: clinical advice for the care of patients with post-operative confusion
}

Maria Bruhn Lundblad, RN, Ward 109, Uppsala University Hospital, Sweden Eva Johansson Hovstadius, RN, Ward 50B, Uppsala University Hospital, Sweden

Key words: Clinical advice delirium intensive care post-operative confusion

E-mail: maria.bruhn.lundblad@akademsika.se eva.johansson.hovstadius@akademiska.se

\section{SUMMARY}

Post-operative confusion is a relatively common and well-known condition in patients who are treated in intensive care units. As many as $72 \%$ of all patients who are treated in intensive care exhibit signs of confusion. It is a psychosis-like condition in which patients can have difficulty in co-ordinating thought and speech, in orientating themselves in time and space, and in receiving and processing information. Some patients can have occasional unreal experiences. Suspicion, fear, anxiety and aggressive behaviour can develop. Certain patients become euphoric whereas others exhibit passive behaviour.

- $\quad$ Signs of post-operative confusion can develop two or three days after the patient's arrival in the intensive care unit and can last for several weeks. The nurse is often the first person who notices the patient's confusion. However, the nurse, together with other members of the healthcare staff may be indaequately experienced to identify and treat the various stages of confusion. This article describes a project to produce clinical advice for intensive care nurses regarding the care of patients with post-operative confusion, based on scientific literature and practical experience.

\section{BACKGROUND}

Post-operative confusion, which may lead to unreal experiences (hallucinations), is a relatively common and well-known condition in patients who are treated in intensive care units (ICUs). The incidence is undefined but has been reported to vary between $7 \%$ and $72 \%$ (Granberg et al. 1996). When patients exhibit signs of confusion, they find themselves in a psychosis-like condition and can have difficulty in coordinating thought and speech, in orientating themselves in time and space, and in receiving and processing information (Granberg-Axèll et al., 2001).

"Unreal experiences" are phenomena which appear in an experienced total wakeful condition or in a condition between wakefulness and sleep; they are experienced as real, and can appear at any time. They tend to appear more frequently in the evening or at night when the patient tries to sleep (Granberg-Axèll et al., 2001). Suspicion, fear, anxiety and aggressive behaviour can develop.
Certain patients become euphoric whereas others exhibit passive behaviour. Signs of post-operative confusion can develop two or three days after the patient's arrival at the ICU and can last for several weeks (Granberg et al., 1999).

There are three main reasons to prevent delirium; it causes higher mortality, longer stay and higher cost. For example, in a study by Ely et al. (2004) despite similar baseline characteristics in a cohort of 275 mechanically ventilated patients, delirium was an independent predictor of higher six-month mortality and was also the strongest independent determinant of length of stay in the hospital.

\section{EXPERIENCES OF TEMPORARY CONFUSION}

Fagerberg and Jönhagen (2002), in their phenomenological study of older people, found that the most common feeling when experiencing temporary confusion, was the experience of threat. For example, one of the informants in their study stated:

"Yes I was so afraid, I feared for my life because I was the only one that knew that we were to be invaded by this other nation. They had told me that and all I wanted was to let the staff know this but it was impossible to get them on my side. I could not succeed no matter how hard I tried."

(Fagerberg \& Jönhagen, 2002, p.341)

Other themes were suspiciousness, wide-open senses and a need to escape, as demonstrated in the following example:

"I was in bed looking up at the ceiling and the lamps were moving across towards me, and I thought "it's coming over me". Yes, I was so afraid but there was nothing I could do to stop it from coming closer and affecting me so I went over to the other bed and lay down there."

(Fagerberg \& Jönhagen 2002, p.343).

The experience of being temporarily confused was described as something the patient felt ashamed of and it brought on a sense of guilt. The feeling of guilt was experienced as a burden when realising that others had observed him or her when he or she was in his or her confusional state. In retrospect it was common that the patient felt regretful over what had happened (Fagerberg \& Jönhagen 2002).

In a qualitative PhD study using interviews and observation to collect data in an orthopaedic surgery setting, patients described anger, fear, insecurity and panic as strong emotional feelings that 


\section{* Unreal experiences: clinical advice for the care of patients with post-operative confusion *}

were connected with their experiences during delirium (Sörensen Duppils, 2003). They were ready to fight with the staff to get away from those feelings. Patients also associated the entry into delirium with some unfulfilled basic needs, for example freezing and thirst. Some patients could describe exactly what happened when they entered into delirium. One man said:

". . . it began with an enormous thirst...it was like fire in my throat, my tongue was stuck up against my palate and then the nightmares began." (Sörensen Duppils, 2003, paper III, p.5).

Patients described their experience of being postoperatively confused as if they were in a dream at the same time as they were awake. Sometimes patients experienced difficulty in communicating with others during delirium. For example, one informant stated:

"I tried to get in contact with the others, but I could not reach them. I do not know if the nurses realised that I was an outsider, they talked with each other and I did not understand what they wanted of me."

(Sörensen Duppils, 2003, paper III, p.7).

One woman said that she argued loudly, but not sucessfully, with the nurses to escape the injection that she thought was going to kill her:

"I do not want that injection", I said. But they did not care... they smiled and were so friendly. But I saw through them, I knew that they were only pretending to be friendly so I would not smell a rat."

(Sörensen Duppils, 2003, paper III, p.7).

In an observational study of intensive care patients during weaning from mechanical ventilation, some patients reported that the unreal experiences they felt while being confused became aggaravated when they were trying to sleep. Other patients said they were afraid to go to sleep because they thought they would die while sleeping (Granberg Axèll, 2001).

\section{RECOGNITION OF POST-OPERATIVE CONFUSION}

The nurse is often the first person who notices the patient's confusion. However, the nurse, together with other members of the healthcare staff, is reported to be ill-prepared to identify and adequately treat the various stages of confusion (Litton, 2003).
The most important step in delirium management is early recognition. Once delirium is detected, efforts should focus on identifying the aetiology. This can be done by assessing for the presence of known risk factors. Strategies for the prevention and management of delirium in the ICU are considered to be important areas for future investigation (ICU Delirium and Cognitive Impairment Study Group, 2006a).

\section{CLINICAL ADVICE}

The objective of our project was to produce an action plan dealing with the care of patients with post-operative confusion. The plan was to be based on scientific literature and practical experience from psychiatry and intensive care. The action plan that we developed consists of clinical advice for nursing staff and an information booklet for patients and relatives affected by the condition. (A copy of the information booklet may be obtained from the authors on request.)

This article describes the clinical advice in detail. Based on our examination of the published literature, as well as our own clinical experience, we developed clinical advice which we divided into three areas:

- $\quad$ preventative measures,

- $\quad$ what can be done once the patient has developed post-operative confusion,

- $\quad$ what ought to be considered after an incident of post-operative confusion.

Nursing interventions are intended to increase both the patient's cognitive status and his or her sense of security and well-being.

\section{Preventative measures}

The nursing staff's role is first and foremost to prevent post-operative confusion by identifying its early signs. These include anxiety, restlessness, irritation and sleep disturbance. If the signs are not noticed and acted upon in time patients risk developing agitation and total confusion. The preliminary stage of an episode of postoperative confusion can last I-3 days. In an acute phase, where the patient is agitated and aggressive, the use of sedatives may be a necessity but the primary course of treatment is always to prevent and eliminate the underlying causes of confusion. The following clinical advice was developed (Table 1):

\begin{tabular}{|l|l|}
\hline Action & Comments \\
\hline $\begin{array}{l}\text { Find out how the patient felt prior to the } \\
\text { operation. }\end{array}$ & $\begin{array}{l}\text { Previous anxiety problems can generate powerful post-operative confusion. Even if } \\
\text { unease or anxiety does not appear in the patient's medical history pre-operative stress } \\
\text { can contribute to post-operative confusion. }\end{array}$ \\
\hline $\begin{array}{l}\text { Find out about the patient's use of alcohol/ } \\
\text { coffee/tobacco. }\end{array}$ & $\begin{array}{l}\text { The effects of alcohol abstinence in addicts can make themselves felt 48- } 72 \text { hours after } \\
\text { the patient has been admitted to ICU. Abstinence from the use of caffeine and nicotine } \\
\text { can lead to post-operative confusion. }\end{array}$ \\
\hline Create a clear, calm and secure environment. & $\begin{array}{l}\text { Remind the patient where he or she is; what the date and time are and explain what is } \\
\text { taking place in his or her surroundings. Try to keep the conversation to concrete facts/ } \\
\text { phenomena in the patient's immediate environment. }\end{array}$ \\
\hline Create a sense of security for the patient. & $\begin{array}{l}\text { Good communication on the part of the carer can help the patient reduce any feeling of } \\
\text { isolation, helplessness and fear. If the patient has problems with their sight or hearing it } \\
\text { is important that he or she has access to the necessary technical aids. }\end{array}$ \\
\hline Reduce unease by being close at hand and by the use of touch or massage. Listening to
\end{tabular}


Prevent stress.

what the patient has to say and talking to them also help. Be conscious of the fact that grief, fear and anxiety can trigger post-operative confusion. The patient should not be left alone. Eye contact and touch are important in order to maintain the patient's attention in a conversation.

Minimise the need to move the patient. Do not expose the patient to activities which can infringe on their integrity, for example, by washing him or her with the door open or in front of other patients or by loudly passing on information about the patient. Respect the patient's territory.

Prevent and treat pain.

Pain can act as a complete block to sleep as well as increasing both the time taken to fall asleep and the number of times the individual wakes up thereby reducing the overall amount of sleep. Be especially attentive to patients who are sedated and/or intubated.

Plan a period of 'winding down' before Give medication so that the patient can get a good night's rest. Bear in mind that unease and sleep disturbance are strongly connected. Stimulate relaxation by the use of massage and music. Warm drinks and warm socks have a peaceful effect.

Provide the opportunity for undisturbed, continuous sleep.

Co-ordinate the timing of various activities involving the patient, stimulate the natural diurnal rhythm, reduce the level of lighting and sound, be quiet yourself. Offer the patient earplugs and eye-shades. Place a sign on the door, stating that the patient is sleeping. Note the patient's periods of sleep on the monitoring list.

Observe whether or not the patient 'goes into his or her shell', no longer talks to other patients, does not read newspapers et cetera.

Passive behaviour can be an early sign of an incipient confusion. Utilise all activities as training opportunities (such as, for example, sitting in the armchair). Remember that passive behaviour can also be responsible for the patient experiencing hallucinations (seeing insects on their body or things in the bed). It can also be responsible for other paranoid thoughts.

Support the patient's relatives so that they can contribute to his or her feeling of peace and calm.

Relatives and friends can play a large role in creating a good and recognisable environment for the patient.

Ask the doctor to go over the patient's medication list.

Look out for medication with anticholinergic effects (neuroleptics, antidepressants, antihistamines, furosemides). Note whether or not the patient was using benzodiazepines even before the operation - the propensity for anxiety increases if the medication is stopped abruptly.

Does the patient have a urinary or respiratory tract infection?

Note and treat disturbances in intestinal/ bladder function.

The infection is in itself a predisposing factor for post-operative confusion.

Constipation and urinary retention can be factors which trigger post-operative confusion.

Ensure that the patient has an adequate arterial oxygen saturation (>95\%, with haematocrit $>30 \%$ ).

Patients who have a lower saturation and haematocrit values more often fall victim to serious post-operative confusion than those with normal or higher values for saturation and haematocrit.

Note whether or not the patient has had periods of low blood pressure (in connection with blood loss, lack of fluid).

Normalise electrolyte and fluid balance.

A low blood pressure can lead to changes in the brain's blood perfusion and blood oxygen level, which in turn can trigger post-operative confusion.

Ensure that the patient has normal glucose levels.

Electrolyte imbalances together with dehydration and the simultaneous use of diuretics are a common cause of post-operative confusion.

Hypoglycaemia can contribute to post-operative confusion.

Table 1. Preventative measures: action plan 


\section{Intervention in cases of post-operative confusion}

The matter of primary importance is to treat the underlying causes. If, for example, the post-operative confusion is as a result of the medication used, cease its use if possible. If it is as a result of lack of sleep then see to it that the patient gets the sleep he or she needs. If insufficient pain relief is the cause then give pain relief so that the patient's estimation of the level of pain experienced (rated on a visual analogue scale of $0-10$, where 10 is greatest pain) is less than 3.

The following advice is given (Table 2):

\section{After post-operative confusion}

The following actions are suggested:

- $\quad$ Many patients have unpleasant memories after their stay in hospital. These should be discussed with the patient afterwards.

- $\quad$ Give both the patient and his or her relatives a copy of the information booklet entitled "For those of you who have had unreal experiences during the period of your medical care on ward 50B".

\section{CONCLUSIONS}

In today's health service nursing staff often fail to notice that patients are entering an acute state of confusion and it is first noticed when the patient is agitated or confused. When the patient becomes agitated or paranoid he or she may need to be sedated, which can lengthen the time spent in ICU and thereby increase the risk for complications.

Early detection of post-operative confusion is important to be able to provide adequate treatment and care. It is therefore important that the nurse learns to recognise the symptoms in order to start (preventative) treatment/nursing interventions.

Evidence-based clinical advice provides an opportunity to assure the quality both of the preventative nursing as well as that of nursing and treatment in instances of post-operative confusion. The nursing period can be shortened and the patient guaranteed more secure nursing care. It has become apparent that there is a large need for information concerning post-operative confusion felt both by those who have been directly affected by unreal experiences, that is the patient, and those who have been indirectly affected, that is their relatives. An information booklet based on evidence can provide a good support for the patient and his or her relatives when it comes to understanding what has happened.

An action plan based on evidence forms a stable basis for the suggested measures. A caregiver who works in accordance with a rational theory has a frame of reference on which to base his or her opinions. It is our hope that this work can contribute to the better nursing of patients suffering from post-operative confusion.

Later this year our ICU will be focusing on the problem of postoperative confusion. We intend to assess all of our patients three times per day, using the Confusion Assessment Method for the ICU (CAM-ICU), which is a delirium monitoring instrument for ICU patients (ICU Delirium and Cognitive Impairment Study Group, 2006b). Using this tool we hope to identify objectively which of our patients are confused, those who are on their way to being confused, or those who have had unreal experiences that we have not noticed.

\section{REFERENCES}

Ely EW, Shintani A, Truman B, Speroff T, Gordon SM, Harrell FE, Inouye SK, Bernard GR, Dittus RS. (2004).Delirium as a predictor of mortality in mechanically ventilated patients in the intensive care unit. JAMA 291 (14), 1753-1762.

Fagerberg I, Jönhagen ME. (2002). Temporary confusion: a fearful experience. Journal of Psychiatric and Mental Health Nursing 9 (3), 339-346.

Granberg-Axèll A, Bergbom I, Lundberg D. (2001). Clinical signs of ICU syndrome/ delirium: an observational study. Intensive and Critical Care Nursing 17(2), 72-93.

Granberg A, Engberg BI, Lundberg D. (1996). Intensive care syndrome: a literature review. Intensive and Critical Care Nursing 12 (3), 173-182. Granberg A, Engberg BI, Lundberg D. (1999). Acute confusion and unreal

\begin{tabular}{|l|l|}
\hline Action & Comments \\
\hline $\begin{array}{l}\text { Acknowledge the patient's feelings but } \\
\text { ignore the confused element in what he or } \\
\text { she may say. }\end{array}$ & Try to give the patient a firm link with reality. \\
\hline $\begin{array}{l}\text { Bear in mind that any attempt to force } \\
\text { the patient to do or accept something } \\
\text { may increase the patient's fear and with it } \\
\text { his or her agitation. }\end{array}$ & $\begin{array}{l}\text { Suitable medication for use in cases of post-operative confusion, and in the promotion of } \\
\text { sleep or the reduction of a feeling of unease is presented in a separate directive. }\end{array}$ \\
\hline $\begin{array}{l}\text { Administer medication as and when } \\
\text { needed. }\end{array}$ & $\begin{array}{l}\text { Check even those medicines which the patient was taking prior to being admitted to the } \\
\text { ICU. }\end{array}$ \\
\hline $\begin{array}{l}\text { At the slightest suspicion of the influence } \\
\text { of medication on the confused state of } \\
\text { the patient ask the doctor to go through } \\
\text { the patient's medication list and remove } \\
\text { any unnecessary items. }\end{array}$ & Where possible try to prevent the patient leaving the ward. \\
\hline $\begin{array}{l}\text { In extreme conditions the use of } \\
\text { compulsory care procedures may be } \\
\text { considered (consult a doctor). }\end{array}$ & \\
\hline
\end{tabular}

Table 2. Intervention measures: action plan 
experiences in intensive care patients in relation to the ICU syndrome. Part II. Intensive and Critical Care Nursing 15 (1), 19-33.

ICU Delirium and Cognitive Impairment Study Group (2006a).

Brain Dysfunction in Critically III Patients. [Online] available at: www.icudelirium.org/delirium (accessed September 2006).

ICU Delirium and Cognitive Impairment Study Group (2006b). Delirium Assessment. [Online] available at:

http://www.icudelirium.org/delirium/training-pages/del.assessment.htm/ (accessed September 2006).

Litton AK. (2003). Delirium in the Critical Care Patient. What the professional staff needs to know. Critical Care Nursing Quarterly 26 (3), 208-213.

Sörensen Duppils G. (2003). Delirium during Hospitalisation. Incidence, Risk Factors, Early Signs and Patients' Experiences of Being Delirious. Unpublished PhD thesis, Uppsala University, Uppsala, Sweden. 